\title{
Komunikasi Bisnis melalui Social Media Trust guna Meningkatkan Customer Engagement pada Pixy Cosmetic
}

\author{
Brizky Amalia Utami *, Kurnia \\ Prodi Ilmu Komunikasi, Sekolah Tinggi Ilmu Komunikasi Inter Studi, \\ Indonesia.
}

*amaliabrizkyy@gmail.com, kurnia.add@gmail.com

\begin{abstract}
Building business communication through Social media trust to increase Customer engagement becomes an interesting discussion. Because nowadays business communication is required to build a sense of trust and intimacy so that customers are willing to engage with the company through social media content. especially with the report that shows a decrease in consumer trust in social media for $41 \%$ because the consumer feel their data privacy can be utilized for the company's business purposes. Also with pixy cosmetics company that has a high potential in Social media trust but their social media engagement rate is still below 50\%. this study analyzes how Social media trust can be influential in increasing Customer engagement.The purpose of this research is to understand business communication built through Social media trust can be directed to increase Customer engagement. Research using quantitative approach by distributing questionnaires through google form and calculated using SPSS through validity, reliability, and simple linear regression tests. The results of this study showed that Social media trusts proved positive can have implications for the increase in Customer engagement of Pixy Cosmetics. customer trust in the communication content of Pixy Cosmetics social media business will increase Customer engagement. The engaged customers will be willing to read Pixy Cosmetics social media content, willing to engage in interactions, even willing to share Pixy Cosmetics business communication content on their social media.
\end{abstract}

Keywords: Business Communication, Pixy Cosmetics, Social media trust, Customer engagement.

Abstrak. Membangun komunikasi bisnis melalui Social media trust untuk meningkatkan Customer engagement menjadi pembahasan yang menarik. Karena saat ini komunikasi bisnis dituntut untuk membangun rasa kepercayaan dan keakraban sehingga customer bersedia untuk engage dengan perusahaan melalui konten media sosial. terlebih dengan adanya report yang menunjukkan tentang penurunan kepercayaan konsumen terhadap media sosial sebanyak $41 \%$ disebabkan konsumen merasa privasi data dapat dimanfaatkan untuk tujuan bisnis perusahaan. Juga dengan perusahaan Pixy Cosmetics yang memiliki potensi Social media trust tinggi tetapi rate engagement media sosialnya masih dibawah $50 \%$. penelitian ini menganalisis bagaimana Social media trust bisa berpengaruh dalam meningkatkan Customer engagement. tujuan penelitian ini adalah untuk memahami komunikasi bisnis yang dibangun melalui Social media trust dapat diarahkan untuk meningkatkan Customer engagement. penelitian menggunakan pendekatan kuantitatif dengan menyebarkan kuesioner melalui google form dan dihitung menggunakan SPSS melalui uji validitas, reliabilitas, dan regresi linear sederhana. Hasil penelitian ini menunjukkan bahwa Social media trust terbukti positif dapat berimplikasi pada peningkatan Customer engagement Pixy Cosmetics. kepercayaan customer terhadap konten komunikasi bisnis media sosial Pixy Cosmetics akan meningkatkan Customer engagement. customer yang engage akan bersedia membaca konten media sosial Pixy Cosmetics, bersedia untuk terlibat dalam interaksi, bahkan bersedia membagikan konten komunikasi bisnis Pixy Cosmetics di media sosial mereka.

Kata Kunci Komunikasi Bisnis, Pixy Cosmetics, Social media trust, Customer engagement. 


\section{A. Pendahuluan}

Komunikasi saat ini telah banyak dibangun melalui media sosial yang dianggap sebagai media efektif dalam keberhasilan komunikasi bisnis (Smits \& Mogos, 2013). Media sosial menyediakan lingkungan digital (Karami et al., 2018) yang dapat digunakan sebagai media komunikasi bisnis ekstensif (Baruah, 2012). Media sosial pada akhirnya telah mendisrupsi cara bisnis berkomunikasi (Yann, 2020) dan merubah cara bisnis terhubung dengan pasar maupun masyarakat luas (Aral et al., 2013).

Komunikasi bisnis saat ini dituntut untuk aktif menyesuaikan konsep komunikasinya agar secara efektif dapat disesuaikan dengan perkembangan media sosial (Grizane \& Jurgelane, 2016). Pemanfaatan media sosial akan membantu bisnis terhubung, terlibat, dan berkembang secara optimal (Newberry, 2018).

Dalam melakukan komunikasi bisnis, saat ini media sosial digunakan untuk membangun kepercayaan (trust) dan menumbuhkan rasa keakraban (engagement) dengan khalayak sasaran melalui strategi komunikasi kreatif (Bergs, 2016). Namun, berdasarkan report data Edelman Trust Barometer 2018 menunjukkan adanya pola penurunan kepercayaan konsumen terhadap media sosial, bahkan kepercayaan pada media sosial hanya mencapai empat puluh satu persen (41\%) secara global (Edelman, 2018).

Lima puluh sembilan persen (59\%) konsumen yang mengikuti akun media sosial merek merasa privasi data dan informasi pribadi belanjanya tidak lagi besifat personal karena perusahaan dapat menggunakan data maupun informasi tersebut untuk tujuan komunikasi bisnis mereka, sehingga komunikasi bisnis semakin dituntut untuk mengatasi krisis kepercayaan konsumen pada ekosistem media sosial (Arnold, 2018). Menciptakan kepercayaan dalam komunikasi media sosial sangat penting dalam bisnis karena hal ini mendasari keberhasilan keeratan hubungan (engagemet) dengan konsumen (Hamer, 2020).

Pixy merupakan salah satu local cosmetic brand yang berhasil memanfaatkan media sosial sebagai sarana komunikasi bisnis, bahkan traffic search media sosial Pixy mencapai 96.40\% menunjukkan bahwa Pixy memiliki potensi Social media trust yang tinggi. Namun, potensi Social media trust pixy belum secara optimal mengarah pada engagement konsumen jika dilihat dari tingkat engagement media sosialnya yang saat ini masih dibawah $50 \%$ (48.77\%) (Similarweb, 2020).

(Purwanto, 2006) dalam Pinuji dan Satiri menyatakan komunikasi bisnis adalah komunikasi yang digunakan dalam dunia bisnis yang mencakup berbagai bentuk komunikasi, baik komunikasi verbal maupun nonverbal untuk mencapai tujuan tertentu (Pinuji \& Satiri, 2019). (Priyatna \& Ardianto, 2008) berpendapat dalam Putri dan Ruliana bahwa bentuk komunikasi bisnis adalah semua pesan yang dikirim dan diterima untuk tujuan resmi, seperti kegiatan bisnis dan suatu pengelolaan organisasi (Putri, A. M., dan Ruliana, 2019). Komunikasi bisnis selayaknya harus dapat dipahami sebagai bentuk relasional oleh konsumen sehingga mereka tidak merasa terganggu dengan konten komunikasi (spam content) serta bersedia terlibat (engaged) dan percaya (trust) dengan konten informasi yang disampaikan (Wolff, 2014). Dalam konteks hubungan pelanggan di media sosial, kepercayaan (trust) merupakan bentuk komitmen komunikasi yang sangat terkait dengan hubungan jangka panjang (Karami et al., 2018) dan menjadi komponen utama dari keeratan (engagement) hubungan pelanggan (Jayasingh, 2019). Komunikasi bisnis melalui Social Media Engagement merupakan bentuk strategi komunikasi yang terkait dengan konten strategy performance dan disesuaikan dengan target market sebuah bisnis. (Perreault \& Mosconi, 2018).

Studi terkait kepercayaan (trust) dalam lingkungan media online semakin menjadi fokus kajian penelitian, khususnya bagaimana kepercayaan dapat membentuk perilaku pelanggan (Tang \& Liu, 2015). Membangun keterikatan pelanggan (Customer engagement) melalui pemanfaatan kepercayaan media sosial (media social trust) sangat penting untuk dapat memastikan bahwa komunikasi bisnis yang dilakukan perusahaan benar-benar sesuai dengan ekspektasi pelanggan (Singhal \& Yerpude, 2018). Media sosial berfungsi sebagai saluran komunikasi yang komprehensif untuk mewujudkan tiga tujuan utama yaitu interaksi pelanggan (customer interaction), keterlibatan pelanggan (Customer engagement), dan kepercayaan (trust) (Behravan \& Rahman, 2012). 
Memahami teori Customer engagement adalah hal yang penting, karena melibatkan pelanggan memiliki manfaat langsung dan tidak langsung dalam sebuah bisnis. karena keterlibatan dapat terjadi hanya apabila suatu hubungan dibentuk berdasarkan kepercayaan dan komitmen (Kumar, 2013). Ghani dalam Chahal \& Rani menyatakan bahwa Engagement merupakan bentuk keterlibatan konsumen untuk dapat terkoneksi dengan media tertentu (Chahal \& Rani, 2017). Customer engagement adalah keterlibatan yang terjadi didasarkan pengalaman pelanggan berhubungan dan berinteraksi dengan objek (misalnya merek, produk, jasa, dan lain-lain) di media tertentu (Brodie et al., 2013). Customer engagement merupakan proses interaksi relasional dari konsumen terkait merek tertentu yang melibatkan aspek kognitif, emosional, dan perilaku yang positif (Hollebeek et al., 2014). Kumar menyatakan dalam bukunya tujuan dari keterlibatan adalah untuk membangun hubungan jangka Panjang (Kumar, 2013). Gallup 2013 dalam Pansari dan Kumar mengatakan bahwa pelanggan yang bersedia terlibat dalam hubungan bisnis cenderung berkontribusi pada profitabilitas, pendapatan, dan pertumbuhan bisnis (Pansari \& Kumar, 2017)

Menurut Yan dalam Schneider Hahn, media sosial memuaskan keinginan konsumen dalam hal keterlibatan (engagement) mereka dengan produk atau merek yang menciptakan partisipasi dan audiensi ( $\Omega$ et al., 2016). Membangun hubungan dengan pelanggan melalui komunikasi media sosial harus dilakukan secara mendalam (Customer engagement) dan diarahkan untuk dapat menciptakan koneksi yang lebih kuat dan bermakna sehingga dapat mendorong pertumbuhan bisnis (wilson, 2020).

Kepercayaan diterima secara luas sebagai komponen utama dari hubungan sosial manusia (Vizard, 2016). Social media trust merupakan kepercayaan yang diperoleh di lingkungan jejaring sosial atas reputasi produk / layanan / organisasi yang membuat pelanggan memiliki keyakinan untuk terlibat dengan komunikasi di media sosial (Golbeck \& Hendler, 2004).

Pelanggan berbagi dan mencari informasi (produk layanan, dan lain-lain) di media sosial didasarkan pada kepercayaan yang diperoleh di lingkungan jejaring sosial (Social media trust) sehingga apabila kepercayaan tersebut tidak terbentuk maka akan membatasi keterlibatan pelanggan (Customer engagement) dengan komunikasi yang dilakukan. Pelanggan yang memiliki tingkat kepercayaan tinggi terhadap merek tertentu, akan memiliki komitmen keterlibatan merek yang semakin tinggi, menurut Sanches-Franco dalam Chahal \& Rani (Chahal \& Rani, 2017). Maka dalam penelitian ini dihipotesiskan bahwa; Media Social Trust berpengaruh positif terhadap meningkatnya Customer engagement.

Berdasarkan hipotesis yang dirumuskan tersebut, penelitian ini bertujuan untuk memahami komunikasi bisnis yang dibangun melalui Social media trust dapat diarahkan untuk meningkatkan Customer engagement.

\section{B. Landasan Teori}

Penelitian ini menggunakan pendekatan kuantitatif dengan menggunakan paradigma positivism yakni memiliki tujuan untuk mengetahui realitas sosial yang terjadi, dengan mengandalkan pengamatan terhadap realitas sosial yang terjadi. Penelitian ini menggunakan teknik random sampling dimana seluruh anggota populasi mempunyai kesempatan yang sama untuk dipilih. Pengumpulan data dilakukan dengan pendistribusian kuesioner secara online menggunakan

google form dengan skala pengukuran likert rentang 1 (sangat tidak setuju) hingga 5 (sangat setuju).

Populasi penelitian ini adalah konsumen yang mengikuti akun sosial media Pixy Cosmetic. Dalam penetapan sampel digunakan rumus yang dikemukakan oleh Lemeshow Stanley sehingga didapatkan 96 (sembilan puluh enam) responden penelitian.

Kuesioner penelitian disusun dengan menggunakan skala item dari

(Jayasingh, 2019); untuk mengukur 4 item pertanyaan tentang kepercayaan konsumen dan serta 5 item pertanyaan tentang keterlibatan konsumen. Data dianalisis menggunakan SPSS dengan tahapan pengujian validitas dan reliabilitas serta pengujian model regresi untuk menilai signifikansi statistik dari hubungan yang dihipotesiskan. 


\section{Hasil Penelitian dan Pembahasan}

Mayoritas responden penelitian ini adalah perempuan (94,8\%), dengan usia rata-rata $18-24$ tahun sebesar $(78,1 \%)$, dan berdomisili di Jabodetabek sebesar $(85,4 \%)$. 53,1\% responden penelitian ini menyatakan bahwa mereka percaya dengan konten pixy cosmetics di media sosial, seperti yang ditunjukan pada Tabel 1 .

Tabel 1. Data Profil Responden

$\left.\begin{array}{|l|l|l|}\hline \text { Deskripsi } & \text { Jumlah } & \text { Persentase (\%) } \\ \hline \text { Usia } & & \\ \hline<18 \text { Tahun } & 2 & 2,1 \% \\ \hline 18-24 \text { Tahun } & 75 & 78,1 \% \\ \hline \text { 25- 29 Tahun } & 12 & 12,5 \% \\ \hline>29 \text { Tahun } & 7 & 7,3 \% \\ \hline \text { Gender } & 5 & 5,2 \% \\ \hline \text { Laki-laki } & 91 & 94,8 \% \\ \hline \text { Perempuan } & 82 & 85,4 \% \\ \hline \text { Domisili } & 12 & 12,5 \% \\ \hline \text { Jabodetabek } & 2 & 2,1 \% \\ \hline \text { Luar Jabodetabek } & 51 & 53,1 \% \\ \hline \text { Lainnya } & 45 & 4,9 \% \\ \hline \text { Alasan mengikuti Pixy } & & \\ \hline \begin{array}{l}\text { Agar dapat berinteraksi- } \\ \text { Dengan konten produk } \\ \text { Pixy }\end{array} & & \\ \hline \text { Karena percaya dengan- } \\ \text { (n=96) }\end{array}\right)$

Hasil uji validitas menunjukan bahwa seluruh indikator masing-masing variable memiliki nilai $\mathrm{r}$ hitung lebih besar dari $\mathrm{r}$ tabel $(0,2006)$, sehingga keseluruhan indikator penelitian dapat dinyatakan valid. Hasil uji reliabilitas menggunakan nilai Cronbach Alpha (CA) yang juga mengkonfirmasi bahwa seluruh data penelitian telah reliabel dengan nilai melebihi 0,60 sebagaimana ditunjukan pada tabel 2 sebagai berikut. 
Tabel 2. Hasil Uji Validitas dan Reliabilitas

\begin{tabular}{|l|c|c|c|}
\hline $\begin{array}{l}\text { Var } \\
\text { iabel }\end{array}$ & $\begin{array}{c}\mathbf{r} \\
\text { Hitung } \\
\mathbf{( >} \\
\mathbf{0 , 2 0 0 6 )}\end{array}$ & $\begin{array}{c}\text { Cronbach } \\
\text { Alpha } \\
\mathbf{( o , 6 0 )}\end{array}$ & Intepretasi \\
\hline$S M T$ & Valid & 0,719 & $\begin{array}{c}\text { Valid dan } \\
\text { Reliabel }\end{array}$ \\
\hline$C E$ & Valid & 0,888 & $\begin{array}{c}\text { Valid dan } \\
\text { Reliabel }\end{array}$ \\
\hline \multicolumn{2}{|c|}{ CE: Customer engagement; SMT: Social media } \\
trust
\end{tabular}

Sebelum dilakukan pengujian hipotesis melalui uji regresi, dilakukan pengujian Asumsi Klasik sebagai prasyarat pengujian kualitas data yang harus dipenuhi untuk melakukan analisis regresi linear sederhana. Dalam penelitian ini uji asumsi klasik dilakukan dengan melakukan tahapan pengujian yaitu: uji linieritas, uji normalitas dan uji heteroskedastisitas.

Hasil uji linieritas ANOVA dalam penelitian ini menunjukkan nilai signifikansi $<0,05$ artinya, tidak terjadi kesamaan varian untuk semua pengamatan pada setiap variabel bebas dalam model penelitian. Pengujian normalitas pada variable Social media trust dan variabel Customer engagement juga menunjukkan bahwa distribusi data penelitian ini terbukti normal dengan nilai signifikansi $>0,05(0,056>0,050)$. Pada hasil uji heteroskedastisitas juga dapat dibuktikan bahwa tidak terjadi heteroskedastisitas pada variabel penelitian, sehingga dapat dinyatakan bahwa ragam residual data penelitian $(>0,05)$ bersifat konstan. Terpenuhinya syarat-syarat pengujian asumsi klasik tersebut membuktikan bahwa model penelitian ini telah memenuhi kriteria model estimasi yang baik (Best Linear Unbiased Estimation).

Tabel 3. Hasil Uji Hipotesis

\begin{tabular}{|l|l|}
\hline & $\mathrm{H} 1$ \\
\hline Hypotesis & SMT->CE \\
\hline Coefficients & 0.874 \\
\hline T. Statistics & $7 \cdot 308$ \\
\hline Significant & 0.000 \\
\hline Result & Supported \\
\hline CE: Customer engagement; SMT: Social media trust \\
\hline
\end{tabular}

Ketiga asumsi telah dipenuhi, selanjutnya melakukan uji regresi linear sederhana 
dengan H0: Social media trust tidak berpengaruh terhadap Customer engagement, dan H1: Social media trust berpengaruh terhadap Customer engagement. Dari hasil uji regresi, didapati t hitung $>t$ tabel atau 7.308 $>1,986$ dan sig $<0,05$ atau 0,000<0,050 sehingga H0 ditolak.

Hasil uji regresi linear sederhana menyatakan bahwa Social media trust berpengaruh positif terhadap Customer engagement dengan nilai koefisien 0,874. Sehingga Social media trust yang dibangun melalui akun instagram Pixy Cosmetics terbukti berpengaruh positif terhadap meningkatnya Customer engagement. Apabila dirumuskan melalui persamaan regresi $\mathrm{y}=\mathrm{bx}$ dapat diketahui bahwa $\mathrm{y}=0,874 \mathrm{x}$. Artinya, apabila Social media trust bernilai konstan maka rata-rata Customer engagement instagram Pixy Cosmetics adalah sebesar 0,874. Meningkatnya Social media trust akan meningkatkan Customer engagement instagram Pixy Cosmetics, sebaliknya penurunan Social media trust juga akan menurunkan tingkat Customer engagement instagram Pixy Cosmetics.

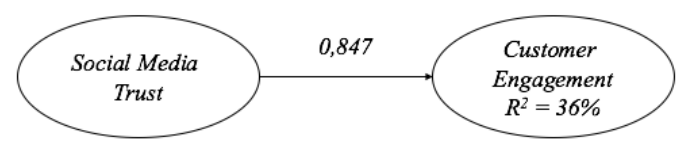

Gambar 1. Model Hasil Penelitian

Sumber: Hasil Olah Data Penelitian, 2021

Nilai koefisien determinasi pada penelitian ini menunjukkan bahwa $36 \%$ variabel Customer engagement dapat dijelaskan oleh Social media trust dan $64 \%$ dijelaskan oleh variabel lain diluar penelitian ini (Gambar 1).

\section{Kesimpulan}

Penelitian ini memahami komunikasi bisnis yang dibangun melalui Social media trust untuk meningkatkan Customer engagement pada Pixy Cosmetics. Hasil penelitian menunjukkan bahwa komunikasi bisnis melalui Social media trust terbukti secara positif dapat berimplikasi pada peningkatan Customer engagement Pixy Cosmetics. Menjaga Social media trust merupakan hal yang krusial bagi komunikasi bisnis Pixy Cosmetic. Apabila Pixy Cosmetic tidak mampu mempertahankan Social media trust dalam komunikasi bisnisnya maka Customer engagement Pixy Cosmetic akan menurun.

Pixy Cosmetics harus mampu menjaga Trust dalam komunikasi bisnis media sosialnya (Social media trust) sehingga customer merasa aman dan percaya saat berinteraksi dengan konten komunikasi bisnisnya. Kepercayaan customer terhadap konten komunikasi bisnis media sosial Pixy Cosmetics akan berdampak pada peningkatan Customer engagement. Customer yang engage dengan Pixy Cosmetics akan bersedia membaca konten komunikasi bisnis Pixy Cosmetic di sosial media dan akan bersedia terlibat aktif dalam interaksi sosial media Pixy Cosmetic. Customer yang engage juga akan bersedia membagikan konten komunikasi bisnis Pixy Cosmetic di sosial media mereka. Engagement yang diperoleh melalui komunikasi bisnis Pixy Cosmetic akan menjadi long-term profit bagi Pixy Cosmetic karena customer yang engage cenderung percaya dan loyal pada produk Pixy serta bersedia merekomendasikan Pixy kepada Customer lain.

Sekalipun hipotesis penelitian ini terbukti signifikan, terdapat beberapa keterbatasan penelitian, diantaranya bahwa hasil temuan ini berlaku hanya pada lingkup objek yang dikaji dalam penelitian yaitu pada konteks komunikasi bisnis media sosial Pixy Cosmetics. Temuan yang berbeda juga dimungkinkan terjadi pada objek penelitian yang berbeda. Kekuatan model penelitian ini masih relatif lemah. Hal ini membuka peluang bagi penelitian selanjutnya untuk dapat mengidentifikasi variabel-variabel lain sebagai variabel penelitian, diantaranya Social Influence, Social Benefit, Entertainment maupun Information Seeking yang juga dapat dipertimbangkan sebagai faktor yang dapat diarahkan untuk meningkatkan Customer engagement. 


\section{Daftar Pustaka}

[1]Aral, S., Dellarocas, C., \& Godes, D. (2013). Social media and business transformation: A Framework for research. Information Systems Research, 24(1), 3-13. https://doi.org/10.1287/isre.1120.0470

[2]Arnold, A. (2018). Consumer Trust In Social Media Is Declining: Here's How Brands Should Change Their Strategies. https://www.forbes.com/sites/andrewarnold/2018/07/29/consumer-trust-in-socialmedia-is-declining-heres-how-brands-should-change-their-strategies/\#67031d476b76

[3]Baruah, T. D. (2012). Effectiveness of Social Media as a Tool of Communication. International Journal of Scientific and Research Publications, 2(5), 1-10. http://www.ijsrp.org/research_paper_may2012/ijsrp-may-2012-24.pdf

[4]Behravan, N., \& Rahman, M. S. (2012). Customer relationship management constructs under social networks towards customers' retention. Australian Journal of Basic and Applied Sciences, 6(7), 271-282.

[5]Bergs. (2016). beginner tips build trust on social media to engage more customers. https://www.semrush.com/blog/beginner-tips-build-trust-on-social-media-to-engagemore-customers/

[6]Brodie, R. J., Ilic, A., Juric, B., \& Hollebeek, L. (2013). Consumer engagement in a virtual brand community: An exploratory analysis. Journal of Business Research, 66(1), 105114. https://doi.org/10.1016/j.jbusres.2011.07.029

[7]Chahal, H., \& Rani, A. (2017). How trust moderates social media engagement and brand equity. Journal of Research in Interactive Marketing, 11(3), 312-335. https://doi.org/10.1108/JRIM-10-2016-0104

[8]Edelman. (2018). Edelman Trust Barometer Special Report: Brand and Social Media 2018. https://www.edelman.com/research/trust-barometer-brands-social-media

[9] Golbeck, J., \& Hendler, J. (2004). Accuracy of metrics for inferring trust and reputation in semantic web-based social networks. Lecture Notes in Artificial Intelligence (Subseries of Lecture Notes in Computer Science), 3257, 116-131. https://doi.org/10.1007/978-3540-30202-5_8

[10]Grizane, T., \& Jurgelane, I. (2016). Social Media Impact on Business Evaluation. Procedia Computer Science, 104(December 2016), 190-196. https://doi.org/10.1016/j.procs.2017.01.103

[11]Hamer. (2020). How to build trust and engagement by being social. https://customerthink.com/how-to-build-trust-and-engagement-by-being-social/

[12]Hollebeek, L. D., Glynn, M. S., \& Brodie, R. J. (2014). Consumer brand engagement in social media: Conceptualization, scale development and validation. Journal of Interactive Marketing, 28(2), 149-165. https://doi.org/10.1016/j.intmar.2013.12.002

[13]Jayasingh, S. (2019). Consumer brand engagement in social networking sites and its effect on brand loyalty. Cogent Business \& Management, 6(1), 1-22. https://doi.org/10.1080/23311975.2019.1698793

[14]Karami, A., Bozbay, Z., \& Arghashi, V. (2018). The Influence of Social media trust on Consumer Behavioral Intention in Tourism Industry. The 2nd Conference on Management \& Business, 1-18.

[15]Kumar, V. (2013). Profitabel Customer engagement (First Edit).

[16]Newberry, C. (2018). 23 Benefits of Social Media for Business. https://blog.hootsuite.com/social-media-for-business/

[17]Perreault, M.-C., \& Mosconi, E. (2018). Social Media Engagement: Content Strategy and Metrics Research Opportunities. Proceedings of the 51st Hawaii International Conference on System Sciences, January. https://doi.org/10.24251/hicss.2018.451

[18]Pinuji, M. F., \& Satiri, S. (2019). PENGARUH USER-GENERATED CONTENT SEBAGAI ALAT KOMUNIKASI BISNIS TERHADAP KREDIBILITAS 
INFORMASI WEBSITE “ TOKOPEDIA " Sekolah Tinggi Ilmu Komunikasi Inter Studi Jl Wijaya II No 62 Jakarta 12160 International University Liaison Indonesia J1 Masjid No 75 Ban. Journal of Creative Communication Volume 1, No 1, 1(1), 19-33.

[19]Priyatna, S., \& Ardianto, E. (2008). Komunikasi Bisnis: Dilengkapi dengan Tujuh Pilar Strategi Komunikasi Bisnis.

[20]Purwanto, D. (2006). Komunikasi Bisnis (3rd ed.).

[21]Putri, A. M., dan Ruliana, P. (2019). Strategi Komunikasi Bisnis Dalam Meningkatkan Kepuasan Tenant. Inter Script: Journal of Creative Communication, 1(1), 1-18.

[22]Similarweb. (2020). Pixy Cosmetic. https://www.similarweb.com/website/pixy.co.id/

[23]Singhal, T. K., \& Yerpude, S. (2018). Impact of Social Media Expressions on Co-creation of Innovation. Amity Business Review, 19(1), 22-32. http://proxy.lib.sfu.ca/login?url=https://search.ebscohost.com/login.aspx?direct=true\&d $\mathrm{b}=\mathrm{bth} \& \mathrm{AN}=133488782 \&$ site $=$ ehost-live

[24]Smits, M., \& Mogos, S. (2013). Association for Information Systems AIS Electronic Library (AISeL) The Impact Of Social Media On Business Performance THE IMPACT OF SOCIAL MEDIA ON BUSINESS PERFORMANCE. Proceedings of 21st European Conference on Information Systems (ECIS). http://aisel.aisnet.org/ecis2013_cr\%5Cnhttp://aisel.aisnet.org/ecis2013_cr/125

[25]Tang, J., \& Liu, H. (2015). Trust in Social Media. Synthesis Lectures On Information Security, Privacy, and Trust.

[26]Vizard, S. (2016). Consumer trust in brands on social media falls as line between marketing and non commercial blurs. https://www.marketingweek.com/consumer-trust-in-brandson-social-media-falls-as-line-between-marketing-and-non-commercial-blurs/

[27]wilson. (2020). Future of Customer engagement. https://hootsuite.com/pages/landing/future-of-customer-engagement

[28]Wolff. (2014). Building trust social engagement. https://www.hatchbuck.com/blog/building-trust-social-engagement/

[29]Yann. (2020). establish more meaningful connections. https://hootsuite.com/pages/landing/establish-more-meaningful-connections

[30] $\Omega$ F. L. S., Ufsm, M., \& Basso, K. (2016). Consumer Trust in and Emotional Response to Advertisements on Social Media and their Influence on Brand Evaluation. 49-71 